\title{
Erratum to: NMR structure note: solution structure of the core domain of MESD that is essential for proper folding of LRP5/6
}

\author{
Jianglei Chen · Qianqian Li • Chia-Chen Liu • \\ Pei Zhou • Guojun Bu $\cdot$ Jianjun Wang
}

Published online: 19 February 2011

(C) Springer Science+Business Media B.V. 2011

Erratum to: J Biomol NMR (2010) 47:283-288

DOI 10.1007/s10858-010-9426-8

One of the author's names was listed incorrectly. Bei Zhou should read as Pei Zhou. We apologise for any inconvenience or embarrassment caused.

The online version of the original article can be found under doi: 10.1007/s10858-010-9426-8.

J. Chen · Q. Li · J. Wang (

Department of Biochemistry and Molecular Biology, School

of Medicine, Wayne State University, Detroit, MI 48201, USA

e-mail: jjwang@med.wayne.edu

C.-C. Liu · G. Bu

Departments of Pediatrics, and Cell Biology and Physiology,

School of Medicine, Washington University, St. Louis,

MO 63110, USA

P. Zhou

Department of Biochemistry, Duke University Medical Center,

Durham, NC 27710, USA 